Gut, 1973, 14, 988-989

\title{
Sieving characteristics of inflamed rectal mucosa
}

\author{
J. RASK-MADSEN
}

From Medical Department F, Glostrup Hospital, Glostrup, Denmark

SUMMARY The sieving characteristics of the normal and inflamed rectal mucosa are studied in three healthy volunteers and five patients with ulcerative colitis. Following rectal instillation of ${ }^{125}$ I-polyvinylpyrrolidone (PVP), the molecular size distribution of labelled PVP in urine samples was determined by Sephadex gel filtration. The results of the study suggest that the increased permeability of the inflamed rectal mucosa to electrolytes and small hydrophilic compounds is due primarily to ultrastructural changes since only the low molecular fractions of PVP were found in the urine.

Since the recent measurements of rectal absorption (Rask-Madsen, Hammersgaard, and Knudsen, 1973), as well as studies of its bioelectrical properties (Edmonds, 1970; Rask-Madsen, 1973), have suggested that the permeability of mucosa is significantly increased in ulcerative colitis, it would seem of some interest to prove whether the leak is due to ultra-visible defects or gross lesions in the epithelium lining the rectal wall. The hypothesis that small hydrophilic solutes diffuse through aqueous-filled pores even in the normal epithelial membranes of the gut has been tested in the human small intestine (Fordtran, Rector, Ewton, Soter, and Kinney, 1965). The results showed that the mucosa actually behaved as if penetrated by aqueousfilled channels, since the molecules were absorbed depending on their molecular size. It has also been stated that 'the colon is less permeable than the small intestine' (Goldschmidt and Dayton, 1919; Curran and Schwartz, 1960), and from a study of urea diffusion Billich and Levitan (1969) concluded that the 'effective' pore radius of the normal colonic mucosa had to be smaller than the molecular radius of urea $(2 \cdot 3 \AA)$, its reflection coefficient being equal to 1 . So polyvinylpyrrolidone (PVP) with a wide range of molecular sizes (average molecular weight 33000 , range 8000-85000) was considered suitable for the investigation of the sieving characteristics of the inflamed mucosa.

\section{Materials and Method}

The study comprised three 'healthy volunteers and five patients suffering from ulcerative colitis localized to the rectum, and belonging to grade II-III Received for publication 29 July 1973. according to the classification of Baron, Connell, and Lennard-Jones (1964). Gel filtration of urine following rectal instillation of ${ }^{125}$ I-PVP (Radiochemical Centre, Amersham) was applied for the estimation of molecular weight distribution of ${ }^{125}$ I-PVP absorbed from the rectum and excreted by the kidneys during the first five hours. In all cases $25 \mathrm{ml}$ of a $0.9 \% \mathrm{NaCl}$ solution containing approximately $125 \mu \mathrm{Ci}$ of ${ }^{125}$ I-PVP was placed in the rectum. Emptying of the bowel was attempted by instilling and evacuating a total of $1000 \mathrm{ml}$ saline at the end of five hours. ${ }^{125} \mathrm{I}$-polyvinylpyrrolidone was always checked for free radioactive iodide as previously described by Rask-Madsen et al (1973), nevertheless all patients were given $0.5 \mathrm{~g}$ potassium iodide the day before and the morning before the investigation for protection of the thyroid. The spectrum of molecular sizes in five-hour urine following a single intravenous injection of ${ }^{125}$ I-PVP (15 $\mu \mathrm{Ci}$ ) was examined in three cases. A 3-ml urine sample containing Blue Dextran 2000 and $25 \mathrm{mg}$ human serum albumin was applied to the top of a $90 \times 1.6 \mathrm{~cm}$ column of a mixture of Sephadex G-200 and G-100 (dry weight ratio 1:2) containing $1 \mathrm{M} \mathrm{NaCl}$ and $0.2 \%$ sodium azide. Filtration was performed at $4^{\circ} \mathrm{C}$ and the flow rate kept at $6 \mathrm{ml} / \mathrm{hr}$; 3-ml fractions of the eluate were collected automatically, and the radioactivity was measured in a well type scintillation counter (Selektronik $\mathrm{A} / \mathrm{S}$, Copenhagen, Denmark). The protein content was determined by measuring optical density at $280 \mathrm{~m} \mu$.

\section{Results}

The molecular size distribution of labelled PVP in the urine samples taken from the controls following 
rectal instillation shows only activity in the low molecular weight fractions (fig). A supplementary study demonstrated that the elution volume of these fractions corresponded well with that of free radioiodide. The molecular size distribution of ${ }^{125}$ I-PVP excreted in the urine of controls following intravenous injection also differed markedly from that of the test solution, although only those high molecular weight fractions higher than albumin were absent in the urine. The results obtained in the patients with active inflammation of the rectum were similar to those obtained in controls, the clearances of high molecular fractions following rectal instillation being insignificantly different from zero (see fig for typical elution curves).

\section{Discussion}

The present study supports the view that theincreased permeability of the inflamed rectal mucosa to both small charged particles like sodium (Rask-Madsen,

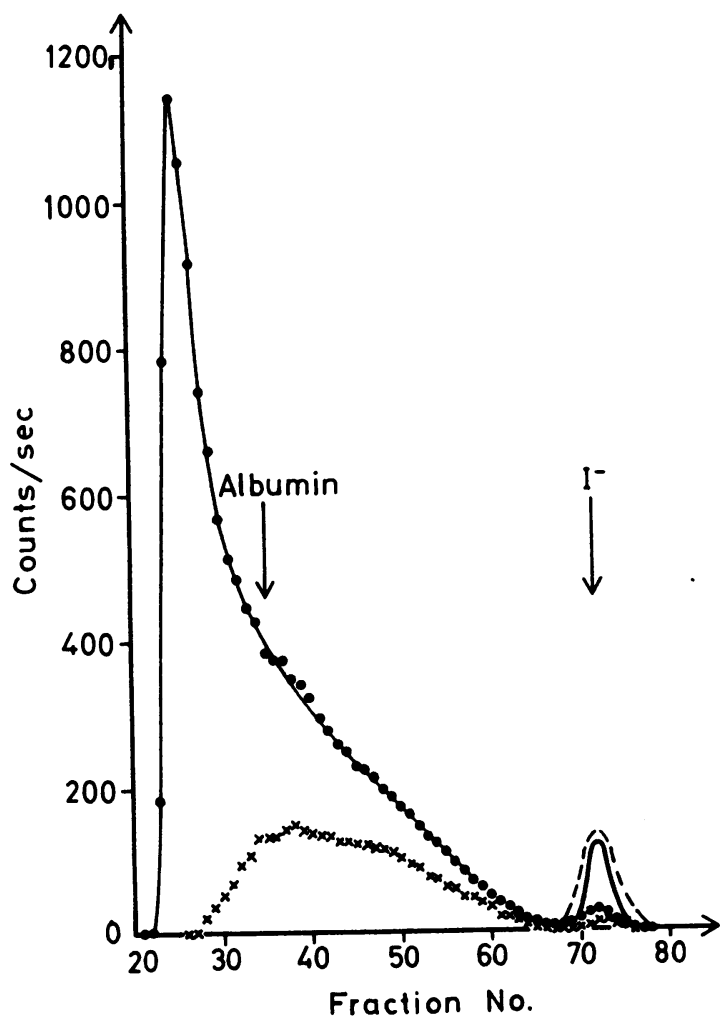

Fig Fractionation on Sephadex of test solution ( -0$)$, urine after intravenous injection $(x-x)$, urine after rectal installation in a control (- $\longrightarrow$ ), and in a patient with ulcerative colitis (grade III) (- -).
1973) and potassium (Lockwood, Harris, and Clark, 1971) and hydrophilic compounds like ${ }^{51} \mathrm{Cr}$-EDTA and ${ }^{57} \mathrm{Co}$-vitamin $\mathrm{B}_{12}$ (Rask-Madsen et al, 1973) is due primarily to ultrastructural changes rather than to macroscopic defects of the diseased epithelium. Other possible explanations may be that the absorption of a compound, which has passed the damaged epithelial barrier, is limited by intact capillary walls and/or a decreased blood flow to the inflamed mucosa. Since the method used in the present study is one of measuring absorption qualitatively and indirectly by urinary excretion, it is important to know to what extent I-PVP is absorbed in the normal state. The fractional absorption of ${ }^{125}$ I-PVP following perfusion of the normal rectum can only account for 0.01 to $0.1 \%$ of the total ${ }^{125} \mathrm{I}$ radioactivity introduced into the rectum (Rask-Madsen et al, 1973), suggesting that the epithelium is practically impermeable to the material. The minimal absorption which the present method would detect is of the same order of magnitude.

To correlate the physiological disturbances outlined above with corresponding morphological changes is not possible to any extent in the present stage of our knowledge. Studies of the inflamed epithelium using electron-dense marker substances might, however, help to define the relationship between function and structure of colonic mucosa in various stages of ulcerative colitis.

This study was supported by grants from the Danish Medical Research Council, the Novo Foundation, and the King Christian $X$ Foundation.

\section{References}

Baron, J. H., Connell, A. M., and Lennard-Jones, J. E. (1964). Variation between observers in describing mucosal appearances in proctocolitis. Brit. med. J., 1, 89-92.

Billich, C. O., and Levitan, R. (1969). Effects of sodium concentration and osmolality on water and electrolyte absorption from the intact human colon. J. clin. Invest., 48, 1336-1347.

Curran, P. F., and Schwartz, G. F. (1960). Na, Cl, and water transport by rat colon. J. gen. Physiol., 43, 555-571.

Edmonds, C. J. (1970). Electrical potentials of the sigmoid colon and rectum in irritable bowel syndrome and ulcerative colitis. Gut, 11, 867-874.

Fordtran, J.S., Rector, F. C.,Jr., Ewton, M.F.,Soter, N., and Kinney, J. (1965). Permeability characteristics of the human small intestine. J. clin. Invest., 44, 1935-1944.

Goldschmidt, S., and Dayton, A. B. (1919). Studies in the mechanism of absorption from the intestine. II. The colon. On the passage of fluid in two directions through the intestinal wall. Amer. J. Physiol., 48, 433-439.

Lockwood, C. M., Harris, J., and Clark, C. G. (1971). Intracellular potassium in diffuse proctocolitis. Lancet, 1. 889-891.

Rask-Madsen, J. (1973). The relationship between sodium fluxes and electrical potentials across the normal and inflamed human rectal wall in vivo. Acta med. scand., 194, 311-317.

Rask-Madsen, J., Hammersgaard, E. A., and Knudsen, E. (1973). Rectal electrolyte transport and mucosal permeability in ulcerative colitis and Crohn's disease. J. Lab. clin. Med., 81. 342-353. 